\title{
Safe Technique of Removal of Left Atrial Thrombus during Mitral Valve Replacement Surgery
}

\author{
Rampada Sarker ${ }^{1}$, Manoz Kumar Sarker ${ }^{1}$, AM Asif Rahim ${ }^{1}$, Abdul Khaleque Beg ${ }^{2}$
}

\begin{abstract}
:
Background: Open mitral operation in patients with massive left atrial thrombus still with high mortality due to intra-operative embolism. To prevent this mortality due to intra-operative embolism and to prevent this danger we practiced a surgical technique which includes careful handling of heart and obliteration of left ventricular cavity by bilateral compression.

Method: We used this technique in patients of severe mitral stenosis with atrial thrombus during mitral valve replacement. Our technique was to obliterate the left ventricular cavity and thus keep the mitral cusps in a coapted position by placing gauge posterior to left ventricle and a compression over right ventricle by hand
\end{abstract}

of an assistant with a piece of gauze. This obliteration prevented passage of fragments of left atrial thrombus towards collapsed left ventricle.

Result: Before practicing this technique, 4 out 9 patients expired due to cerebral embolism. But after implementation of this technique in 17 patients no mortality or morbidity occurred.

Conclusion: This technique of removal of left atrial thrombus during mitral valve replacement may be a safe procedure for preventing peroperative embolism.

Key words: Safe technique, Removal of LA thrombus, Mitral valve replacement.
Introduction:

Left atrial thrombi are common cause of embolisation ${ }^{1}$; especially in patients with mitral valve abnormalities ${ }^{1,2}$ and atrial fibrillation 3,4 . Left atrial enlargement is common in severe rheumatic mitral stenosis ${ }^{1 ., 5}$. Exact etiology is not known but increased left atrial pressure and weakening of left atrial wall by rheumatic pancarditis are implicated in its development ${ }^{1,2}$. The enlarged left atrium is associated with blood stasis and thrombus formation among patients with mitral stenosis with atrial fibrillation $^{6,7}$. The presence of massive left atrial thrombus still clouds with uncertainity the otherwise standardised mitral operation ${ }^{8}$. Although open techniques have made the removal of the thrombus possible, the occasional massive and usually friable thrombotic mass constitutes and usually friable thrombolic mass constitutes a very real hazard of intra operative embolism ${ }^{8}$. To prevent or minimize this danger, a number of surgical manuvers have been proposed $^{9,10,11,12,13}$. Our experience in facing this problem prompted us to reconsider our technique and

1. Department of cardiac surgery, NICVD, Dhaka

2. Department of Anesthesiology and Intensive Care Unit, National Institute of Cardiovascular Diseases, Dhaka. introduce some modifications which may eliminate the danger of intra-operative fragment embolisation.

\section{Methods:}

This retrospective study was carried out during the period of january 2014 to march 2016 in the Department of Cardiac Surgery in National Intitute of Cardiovascular Diseases (NICVD) and Hospital, Dhaka, with permission of academic council of the institute. There were total 26 patients of severe mital stenosis with left atrial thrombus undergoing mitral valve replacement. In 9 out of 26 patients we practiced the previous conventional technique and in 17 patients we used the new technique of thrombus removal. Data were collected retrospectively from records of operation theatre at Cardiac Surgery Department and our Cardiac Surgery Units follow-up sheet.

\section{Surgical technique :}

Cardiopulmonary bypass was established with standard procedure of aortic and bicaval canulation. The heart was arrested by moderate antegrade hypothermic bloodcardoplagic arrest. Two pieces of gauge were placed under the left verticle. Another piece of gauge was placed over the right ventricle (Figure-1) 


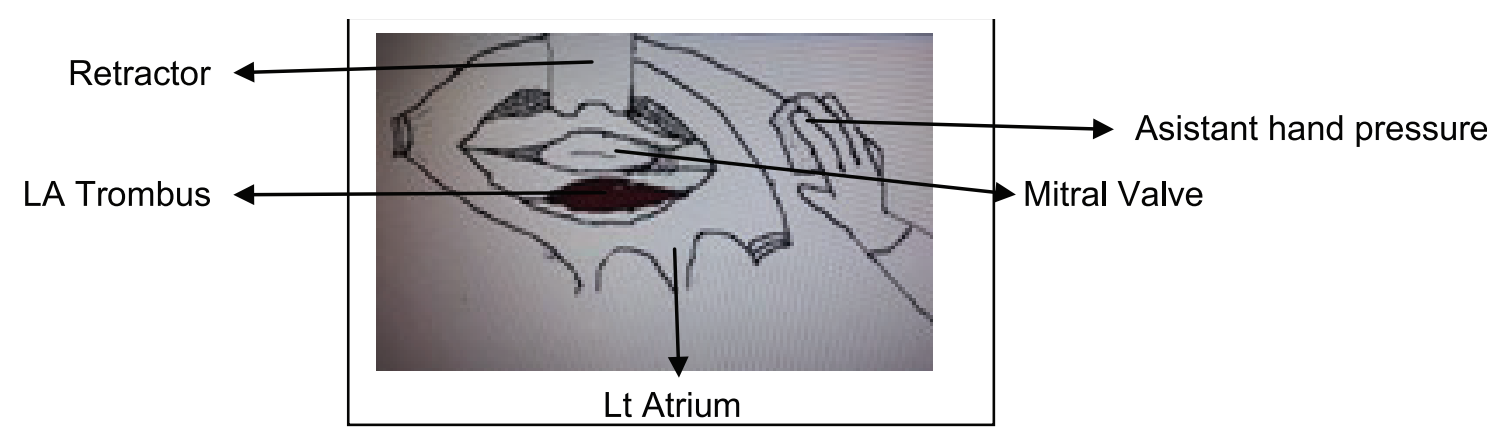

Fig.-1: Safe technique of thrombus removal from left atrium by obliteration of left ventricular cavity by pressure.

A gentle pressure was exerted by an assistant on the gauge over the right ventricle with his right palm of the hand sufficient enough to collapse left ventricle. Left atriotomy was done, retractor to left atriotomy was introduced. Careful handling was ensured to avoid disrupting the thrombotic mass. A plane of cleavage was created by holding the anterior lip of the atriotomy and making a blunt disection thereby separting the thrombus from the wall. The intracardiac sucker was placed within the left atrial carvity was washed out thrombus and valsalva manuver were performed, there by aspirating pulmonary veins. gauges were removed after releasing compression on right ventricle. Mitral valve replacement was completed, left atrium was closed. cross-clamp was released after proper and adequate de-airation.The patients were weaned from cardiopnlmonary bypass and chest was closed. Cardipulmonary by pass time aortic cross-clamp time were collected from operation theatre record book.Postoperatively all palients data were collected from operation theatre recordbook.Post-operatively all palients were admitted into intensive care unit where record of any sytemic or cerebral embolism or, any ventilation problem or mortality were searched from registered data. Oral anti coagulant warfarin was started from first postoperative day.

\section{Result:}

Mitral Valve Replacement were performed in both groups of patients. Mean age of the patients (table-I) were 41.35 years in our new technique group (Group-II). Seven were male and 10 were female. Mean weight was $51.59 \mathrm{~kg}$. All of 17 patients with new technique (group-II) were free from cerebral embolism (table-II). Mean age of patients of conventional technique group (Group-I) was 40.22 years. Six were male and three were female, mean body weight was $49.78 \mathrm{~kg}$. Four patients (44.44\%) out of 9 patients of old technique group(group-I) expired due to cerebral embolization in old technique group, among them 2 were male and 2 were female (table-II).

Table-I

Demographic data

\begin{tabular}{|c|c|c|c|c|c|c|c|}
\hline \multirow[b]{2}{*}{ Group-I(Old technique) } & \multirow{2}{*}{$\begin{array}{c}\text { Age(mean)years } \\
40.22\end{array}$} & \multirow{2}{*}{$\begin{array}{c}P \text { value } \\
0.125\end{array}$} & \multicolumn{2}{|c|}{ Sex } & \multirow{2}{*}{$\begin{array}{l}P \text { value } \\
0.430\end{array}$} & \multirow{2}{*}{$\begin{array}{c}\text { Body Wt. } \\
49.78\end{array}$} & \multirow{2}{*}{$\begin{array}{c}\text { P value } \\
0.212\end{array}$} \\
\hline & & & F 3(33.3\%) & M 6(66.7\%) & & & \\
\hline Group-II & (New technique) & 41.35 & & F $10(58.8 \%)$ & M 7(41.2\%) & & 51.59 \\
\hline
\end{tabular}

Table-II

Outcome of two groups

\begin{tabular}{lcccc}
\hline & Total pt. & THROMBO & No THROMBO & P value \\
& & EMBOLISM & EMBOLISM & 5 \\
Group-I (Conventional) $\mathrm{n}=9$ & 9 & 4 & 17 & 0.001 \\
Group-II (New Technique) $\mathrm{n}=17$ & 17 & 0 & & \\
\hline
\end{tabular}




\section{Discussion:}

Removal of an organized thrombus from left atrium can be challenging especially when it is huge in size and the presence of dense adhesion and absence of cleavage plane makes its removal difficult ${ }^{14}$. and under such circumstances residual organized material can be left ${ }^{14}$. Gallo and colleagues ${ }^{8}$ practiced a technique that included occlusion of mitral valve orifice by a 24F Foley catheter to prevent entry of thrombus fragments into left ventricle. They practiced in 22 patients without any mortality or morbidity where as 7 out of 8 patients expired in their previous technique of left atrial thrombus, like their experience we lost 4 out of 9 patients with previous conventional technique and all of 17 patients with new technique of thrombus removal from left atrium were free from cerebral embolism .Our Technique is similar to them. Because the occluded mitral valve orifice and we occluded mitral valve cavity so that thrombus cannot get entry through mitral valve orifice. Excision of the small atrial thrombus does not present any surgical difficulty but a large intra-cavitery thrombotic mass creates a serious chance of intra-operative embolization ${ }^{8}$.The goal of this new technique was to avoid inadvertent handling, carefully performing atriotomy and introducing the retractors. Obliteration of left ventricular cavity avoided entry of fragments of thrombus into the left ventricle. Finally wall suction, vulsalva maneuver and thorough left atrial washing removed virtually all residual fragments. Our study was retrospective with only 17 patients. A large scale prospective study in multiple centers can judge safety of our technique.

\section{Conclusion:}

Our technique of removal of left atrial thrombus during mitral valve replacement by occlusion of left ventricular cavity by gentle compression is safe and prevents cerebral embolization.

\section{Acknowledgement:}

I would like to express my thankful acknowledgement to Kabita Rani Podder, ICU in-charge, and Farida Yasmin, OT in-charge, of NICVD for their cooperation during collection of data for this study.

\section{Conflict of interest- None.}

\section{References:}

1. Hofmann T, Kasper W, Meinertz T, Giebal A, Just $\mathrm{H}$. Echocardigraphic evaluation of patients with clinically suspected aterial emboli. Lancet 1991; 336:1421-4

2. Chiang CW, Lin PC, Fang BR, Kuo CT, Lee YS, Chang $\mathrm{CH}$. "Sand-drift" echoes and thrombus formation in the left atrium. Am Heart J, 1988; 115:909-11

3. Mugge A, Danial WG, Hausmann D, Godke J, Wagenbreth I, Lichten D. Dignosis of left atrial appendage thrombi by trans-esophagical echocardiography; clinical implications and followup. Am J Cardiac Imaging, 1990; 4: 173-9

4. Aschenberg W, Singlov V, Kremer P, Schluter M, Bleified W. Thromben in linker herzohr tratz adaquater antikoagulation. Disch Med Wschr1982; 112: $663-8$

5. Darwazah AK and Sayed EI. Giant Left atrium assiciated with massive thrombus formation. Thrombosis J 2013;11:5

6. DiEusanio G, Gregorini R, Mazzola A, Clement G, Procaccini B, Caverra F, Tarasch F, Esposito G Dinardo W, Diluzio V. Giant left atrium and mitral valve replacement risk factor analysis. Eur $j$ Cardiothorace surg 1988; 2: 151-9

7. Farman MT, Sial JA, Khan N, Rahu QA, Tasneem H, Ishag $\mathrm{H}$. Sever mitral stenosis with atrial fibrillationharbinger of thromboembolism $J$ Pak Med Assoc 2010; 60 (6) : 439-43

8. Gallo JI, Ruiz B, Duran CMG. A Safe technique for removal of massive left atrial thrombus. Ann Thorac Surg 1981; 31(3): 283-4

9. Dubost $\mathrm{C}$, Blondeau $\mathrm{P}$, D'Allaines $\mathrm{C}$ et at. Thrombosis massives de l'oreillette gauche, Ann Chir Thorac Cardiavasc1977; $16: 45$

10. John S, Muralidharan S, Jaira PS et al. Massive left atrial thrombus complicating mitral stenosis with atrial fibrillation: results of surgical treatment. Ann Thorac Surg 1976; 21: 103.

11. Peterson LM, Fisher RD, Reis RL, Morrow AG, Cardiac operation in patients with left atrial thrombus: incidence and prevention of postoperative embolism. Ann Thorac Surg 1969; 8: 402

12. Ullah SR, Kluge TH, Hill JD et al. Left atrial thrombi in mitral valve disease. J Thorac Cardiovasc Surg 1971; 62: 932

13. Versha JJ, Ludington LG, Walker WJ et al. The occurrence and management of left atrial thrombi in mitral valve surgery. J Cardivasc Surg 1974; 15:516

14. Lim C, Rhyu WH, Lee Y, Choh JH. Managemt of left atrial myocardium after extensive thrombectomy. Ann Thorac Surg 2005;79: 11-2. 